\title{
AUC Dosing to Last Concentration Normalized by Weight
}

National Cancer Institute

\section{Source}

National Cancer Institute. AUC Dosing to Last Concentration Normalized by Weight. NCI

Thesaurus. Code C92305.

The area under the curve (AUC) from the time of dosing to the last measurable concentration divided by the weight. 